\title{
In vivo targeted killing of prostate tumor cells by a synthetic amoebapore helix 3 peptide modified with two $\gamma$-linked glutamate residues at the $\mathrm{COOH}$ terminus
}

\author{
LORI HOLLE ${ }^{1}$, WEN SONG $^{1}$, ERIC HOLLE ${ }^{1}$, JENNIFER NILSSON $^{1}$, YANGZHANG WEI $^{1,2}$, \\ JINHUA LI ${ }^{1}$, THOMAS E. WAGNER ${ }^{1,2}$ and XIANZHONG YU ${ }^{1,2}$ \\ ${ }^{1}$ Oncology Research Institute of the Greenville Hospital System, Greenville, SC 29605; \\ ${ }^{2}$ Department of Biological Sciences, Clemson University, Clemson, SC 29634, USA
}

Received December 17, 2008; Accepted March 9, 2009

DOI: 10.3892/mmr_00000112

\begin{abstract}
We previously designed a pro-cytolytic peptide to target prostate-specific membrane antigen (PSMA)-positive prostate tumor cells. The backbone of the peptide was derived from the cell lytic amoebapore H-3 domain, which becomes completely inactive upon modification by two glutamate residues linked to the $\varepsilon$-amide group of the $\mathrm{COOH}$-terminal lysine through $\gamma$-linkages (H-3Glu2). This modified $\mathrm{H}-3$ domain regains its lytic activity against PSMA-positive cells (LNCaP) after the $\gamma$-linked glutamate residues are cleaved by PSMA. Our previous in vitro results demonstrate that the modified amoebapore peptide has strong cytolytic activity towards PSMA-positive cells and very little activity towards PSMA-negative cells. In the present study, the in vivo efficacy of this modified peptide was examined in human LNCaP prostate tumor xenografts in nude mice. The results showed significantly decreased tumor size and PSA levels in treated mice as compared to control mice. As well, 5/12 of the treated mice were tumor-free. Peptide distribution studies showed that peptide levels in the prostate tumors maintained a steady concentration for approximately $6 \mathrm{~h}$. Single-dose toxicity studies showed no toxic effects of the peptide when administered intraperitoneally or intravenously at a dose of $30 \mathrm{mg} / \mathrm{kg}$.
\end{abstract}

\section{Introduction}

Prostate cancer is the second leading cause of cancer-related death among American men (1). Currently, there is no therapy with a significant survival benefit for men with androgenrefractory prostate cancer (2), as the efficacy of the available clinical chemotherapeutic regimens is limited by systemic toxicities. To improve the selectivity of tumor cell killing by

Correspondence to: Dr Xianzhong Yu, Oncology Research Institute, Greenville Hospital System, 900 West Faris Road, Greenville SC 29605, USA

E-mail: xyu@ghs.org

Key words: amoebapore, prostate cancer, cytolytic peptides therapeutic agents, tumor-activated prodrugs have been exploited with a variety of cytotoxic agents (3-13). The selectivity of these prodrugs is ensured by the tumor cell- and tumor micro-environment-restricted expression of proteases, such as prostate-specific antigen (PSA), prostate-specific membrane antigen (PSMA), urokinase-type plasminogen activator (uPA) and matrix metalloproteinases (14).

We designed a novel pro-cytolytic peptide with a backbone consisting of an amoebapore H-3 domain modified by two $\gamma$-linked glutamate residues at the $\varepsilon$-amino group of the $\mathrm{COOH}$ terminal lysine residue (7). The H-3 domain was chosen as the peptide backbone, since in vitro studies have indicated that this domain of the amoebapore peptide exhibits high levels of pore forming activity. Our previous results showed that the modified peptide exhibited little cytolytic activity toward PSMA-negative cells, such as PC-3 cells (7). On the other hand, this peptide exhibited strong cytolytic activity toward PSMA-positive LNCaP cells in a concentrationdependent manner. The carboxypeptidase inhibitor 4,4phosphonicobis (butane-1,3-dicarboxylic acid) inhibited this activity. Moreover, this peptide also exhibited cytolytic activity toward PSMA cDNA-transfected PC-3 cells (7).

In the present study, the in vivo efficacy of this modified peptide against tumor cells was examined in human LNCaP prostate tumor xenografts in nude mice.

\section{Materials and methods}

Peptide synthesis. The amoebapore peptide was synthesized and purified by NeoMPS Inc., formerly known as Multiple Peptide Systems (San Diego, CA). The sequence is shown in Warren et al (7). The peptide was stored at $-80^{\circ} \mathrm{C}$ upon arrival. Prior to use, the amoebapore peptide was reconstituted in sterile PBS (Fisher Scientific) at a final concentration of $1 \mathrm{mg} / \mathrm{ml}$.

Cell line for in vitro and in vivo experiments. LNCaP prostate cancer cells were purchased from the American Type Cell Culture Collection (ATCC; Manassas, VA). The cells were cultured in RPMI-1640 media (Hyclone; Logan, UT) supplemented with $10 \%$ FBS (Hyclone), $1.5 \mathrm{~g} / 1$ sodium bicarbonate (Hyclone), 4.5 g/l glucose (Sigma; St. Louis, MO), $10 \mathrm{mM}$ HEPES (Gibco; Carlsbad, CA) and $1 \mathrm{mM}$ sodium pyruvate 
(Gibco), and were grown at $37^{\circ} \mathrm{C}$ in an atmosphere containing $5 \% \mathrm{CO}_{2}$.

In vitro cell viability assay. In order to determine the in vitro cytolytic activity of the modified peptide, the CellTiter-Glo Luminescent Cell Viability Assay (Promega; Madison, WI) was used. This assay measures cell viability by assessing the amount of adenosine-5'-triphosphate (ATP) present. On day 0, the $\mathrm{LNCaP}$ cells were plated in an opaque-walled 96-well tissue culture plate (Fisher) at a density of 40,000 cells/well in a volume of $100 \mu \mathrm{l}$. Approximately $24 \mathrm{~h}$ after plating, the media were carefully removed from the cells and replaced with $100 \mu \mathrm{l}$ of various concentrations of modified peptide, $1 \%$ Triton X-100, or PBS. The cells were treated for $4 \mathrm{~h}$, and then the CellTiterGlo Luminescent Cell Viability Assay was conducted according to the manufacturer's protocol. The Lumistar (BMG Labtech) was used to measure the luminescence (RLU) of each sample. The gain was set at 150 to read all the samples. The percent decrease in ATP was calculated as follows: [(sample RLU untreated RLU)/untreated RLU] x 100.

Toxicity studies. All toxicity studies were conducted by MDS Pharma Services (Taipei, Taiwan). Briefly, the modified peptide was administered intravenously (i.v.) to a group of 5 CD-1 (Crl.) derived male mice weighing $22 \pm 2 \mathrm{~g}$ at an initial dose of $30 \mathrm{mg} / \mathrm{kg}$ in a vehicle of PBS $\mathrm{pH}$ 7.4. The animals were monitored for the presence of acute toxic symptoms (mortality, convulsions, tremors, muscle relaxation, sedation) and autonomic effects (diarrhea, salivation, lacrimation, vasodilatation, piloerection) during the first $5 \mathrm{~min}$. Mortality was also subsequently noted $3,24,48$ and $72 \mathrm{~h}$ after treatment. The experiment was repeated once, though with intraperitoneal (i.p.) injection.

$I^{125}$ labeling of the peptide. In order to label the peptide with $\mathrm{I}^{125}$, a modified form of the peptide was synthesized in which a phenylalanine at the C-terminal end was replaced with a tyrosine. This tyrosine-containing peptide is as potent as the original H-3 peptide, as demonstrated by in vitro cell killing assays (data not shown). The tyrosine-modified peptide was labeled with ${ }^{125}$ using Iodo-Bead Iodination Reagent (Pierce; Rockford, IL). In brief, 2 beads were washed with PBS and then incubated for $5 \mathrm{~min}$ with $1 \mathrm{mCi} \mathrm{I}^{125}$. Modified peptide $\left(2 \mathrm{mg}\right.$ ) dissolved in PBS was added to ${ }^{125}$-labeled beads and incubated at room temperature for $12 \mathrm{~min}$. After $12 \mathrm{~min}$, the peptide was removed from the beads. Zeba Desalt Spin Columns (Pierce; Rockford, IL) were used to remove unincorporated $\mathrm{I}^{125}$ from labeled peptide. The $\mathrm{I}^{125}$ activity of the peptide was determined using a scintillation counter.

Mice used for in vivo experiments. All mice used for in vivo experiments were male and of the CByJ.Cg-Foxn1 ${ }^{\text {nu}} / \mathrm{J}$ strain. Mice were obtained from Jackson Laboratories (Bar Harbor, $\mathrm{ME}$ ) and were 3-5 months old at time of use. The mice were housed according to the standard IACUC protocol for nude mice.

Tumor inoculation. LNCaP cells were harvested via washing with $1 \mathrm{X}$ PBS followed by trypsinization according to standard methods. LNCaP cell pellets were collected by centrifugation at $300 \mathrm{x} \mathrm{g}$ for $5 \mathrm{~min}$, and then resuspended at a final concentration of $7 \times 10^{6}$ cells $/ \mathrm{ml}$ in $50 \%$ BD Matrigel Basement Membrane Matrix High Concentration (BD Biosciences; San Jose, CA ) and 50\% ice cold PBS (Fisher Scientific; Pittsburg, PA). This LNCaP cell suspension $(0.5 \mathrm{ml})\left(3.5 \times 10^{6}\right.$ cells $)$ was injected subcutaneously into the right flank of each mouse. Visible tumors generally appeared 3-4 weeks after tumor inoculation.

Tissue distribution studies. Approximately $150 \mu \mathrm{g}(7.5 \mu \mathrm{CI})$ of the peptide was injected i.p. into $14 \mathrm{CByJ} . \mathrm{Cg}-\mathrm{Foxn} 1^{\text {nu }} / \mathrm{J}$ male mice inoculated with $\mathrm{LNCaP}$ cells as described above, with visible tumors at the time of the distribution study. After i.p. injection of $\mathrm{I}^{125}$-labeled peptide, the mice were sacrificed at four separate time points: 1, 3, 6 and $24 \mathrm{~h}$. There were 3 mice in each group, and two mice in an additional $30-\mathrm{h}$ group. The tissues, including whole blood, heart, liver, lung, kidney, spleen, testes, tumor, brain and muscle tissues, were removed and weighed. A scintillation counter was used to determine the counts per minute in each type of tissue.

In vivo tumor killing studies. Approximately 10-14 days after tumor inoculation, $200 \mu \mathrm{g}$ of the peptide was injected i.p. into mice. Mice were injected twice a week for 7 weeks. All modified peptide injections were carried out i.p.

Prostate-specific antigen determination. To monitor the progression of the tumor as well as the effectiveness of the modified peptide treatment, PSA levels were measured in the mouse serum using the Human Prostate Specific Antigen ELISA Kit (Alpha Diagnostic International; San Antonio, TX) according to the manufacturer's protocol. Standard procedure was used to obtain blood from the tail of the mouse. Whole blood was collected in a non-heparinized Natelson blood collecting tube (Fisher), transferred to a $1.5-\mathrm{ml}$ tube and centrifuged at $5000 \mathrm{x} \mathrm{g}$ for $5 \mathrm{~min}$. The serum was then transferred to a fresh $1.5-\mathrm{ml}$ tube and stored at $4^{\circ} \mathrm{C}$ until use.

Statistical analysis. Statistical analysis was performed with Graphpad Prism. Two-tailed, non-parametric and unpaired t-tests were used to test for significant differences between groups when appropriate.

\section{Results}

ATP levels in modified peptide-treated versus untreated LNCaP cells. LNCaP cells treated with modified peptide showed a greater percent decrease in ATP levels compared to untreated cells. Prior to treating mice with the modified peptide, an in vitro cell viability assay was conducted to determine whether or not the peptide was effective in cultured cells. As described in Materials and methods, $\mathrm{LNCaP}$ cells were plated and then treated for $3 \mathrm{~h}$ with various amounts of modified peptide. A cell viability assay was then carried out, which measured the viability of cells by analyzing ATP levels. Fig. 1 shows that when LNCaP cells were treated with $200 \mu \mathrm{g}$ of modified peptide, the percent decrease in ATP levels was $\sim 35 \%$. Overall, as the amount of modified peptide used to treat the LNCaP cells was increased, a higher percent decrease in ATP levels was observed. 


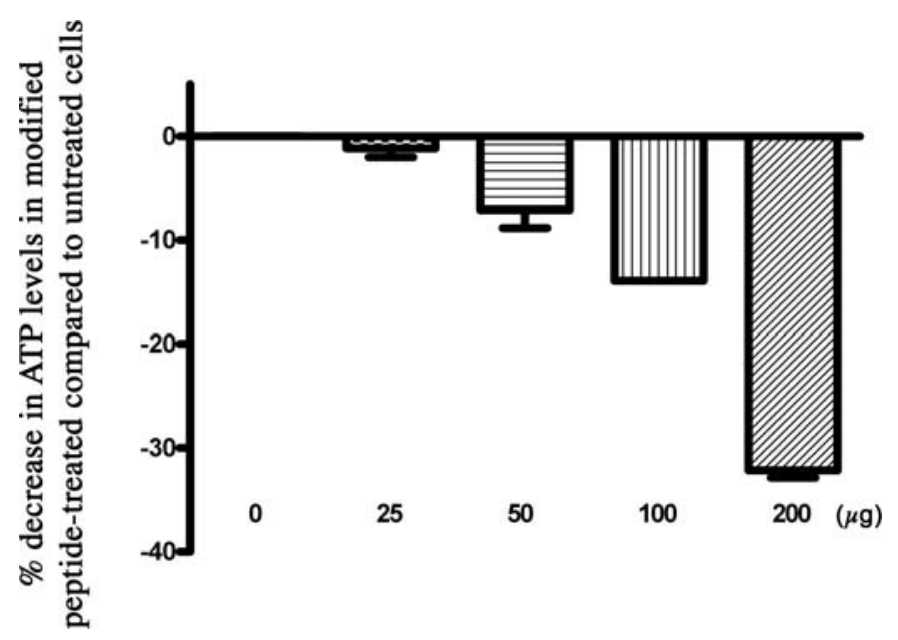

Figure 1. Modified amoebapore peptide decreases cell viability in vitro. The percent decrease in adenosine-5'-triphosphate (ATP) levels upon treatment with the peptide is shown. $\mathrm{LNCaP}$ cells were treated with various amounts of modified peptide for $\sim 3 \mathrm{~h}$, then ATP levels were measured using the CellTiter-Glo Luminescent Cell Viability Assay Kit. As the amount of peptide was increased, a higher percent decrease in ATP levels was noted. The assay was carried out in duplicate. The calculation for percent decrease in ATP is explained in Materials and methods.

Toxicity in modified peptide-treated mice. No significant toxicity was apparent in mice injected with modified peptide. There was no inhibition of any CYP450 enzymes and no observed toxicity associated with the peptide administered intraperitoneally (i.p.) or intravenously (i.v.) in single-dose studies at $30 \mathrm{mg} / \mathrm{kg}$ (AdverseEventProfile ${ }^{\mathrm{TM}}$, MDS Pharma). Slight-to-moderate effects on limb tone were observed at the maximum tolerated dose (4 days at $50 \mathrm{mg} / \mathrm{kg}$ i.v.) in sensitive SCID mice.

Peptide tissue distribution using the modified peptide. Tissue uptake after single-dose i.p. injection of radiolabeled tyrosinemodified peptide was evaluated in the tumor, blood, kidney, testes, muscle, lung, liver, heart, spleen, and brain tissues of the mice sacrificied at 1, 3, 6 and $24 \mathrm{~h}$. As shown in Fig. 2A, the modified peptide reached peak levels in most of the tissues after $1 \mathrm{~h}$, with the exception of tumor and liver tissues, in which the peak level was reached after $\sim 3 \mathrm{~h}$. The accumulation of the modified peptide in muscle tissue was very poor, and levels in brain tissue were essentially equal to background levels. Peptide levels in most of the tissues dropped significantly after $6 \mathrm{~h}$ and reached a very low level comparable to the background control, except in lung tissue. Peptide levels were not significantly increased in tumor tissues compared to lung, spleen and testes tissues. This is not surprising as the peptide is targetactivated, not target-delivered. The peptide maintained a steady concentration in tumor tissues for $\sim 6 \mathrm{~h}$ after reaching peak levels at $\sim 3 \mathrm{~h}$. Modified peptide levels in the blood (Fig. 2B) were highest after $1 \mathrm{~h}$, then continuously dropped to $\sim 0$ at $24 \mathrm{~h}$.

Tumor incidence and PSA levels. In vivo tumor killing studies showed that mice treated with modified peptide displayed a significant decrease in tumor incidence and PSA levels. The efficacy of the in vivo tumor cell killing of our modified peptide was studied using human LNCaP xenografts in nude mice. Mice treated with the modified peptide were monitored for tumor incidence as well as PSA levels. PSA levels were measured at $\sim 2$-week intervals once tumors in the control mice were visible (data not shown), and tumor appearance was monitored daily. Fig. 3 shows a distribution plot of PSA levels in the control and treated mice after 7 weeks of injection. It was noted that the majority of the treated mice $(8 / 12)$ had very low levels of PSA compared to the control mice. The actual serum PSA values as well as the tumor incidence at the end of week 7 of the modified peptide treatment are shown in Table I. When the average PSA levels in the treated mice $(52.9 \mathrm{ng} / \mathrm{ml})$ were compared to the average PSA levels in the control mice (79.4 ng/ml), an $~ 33 \%$ ( $\mathrm{p}=0.3795$ ) decrease in serum PSA levels was noted in the treated mice. Table I also shows that $5 / 12$ mice in the treated group had no visible tumors and no detectable levels of serum PSA. Additionally, there appeared to be a significant body weight decrease in the control group compared to the peptide-treated group, as shown in Fig. 4 and Table II $(\mathrm{P}<0.05)$. The average weight of the control mice was $19.95 \mathrm{~g}$, while the average weight of the treated mice was $22.06 \mathrm{~g}$. Therefore, the overall health of the treated mice was better than that of the control mice at the end of the study.
A

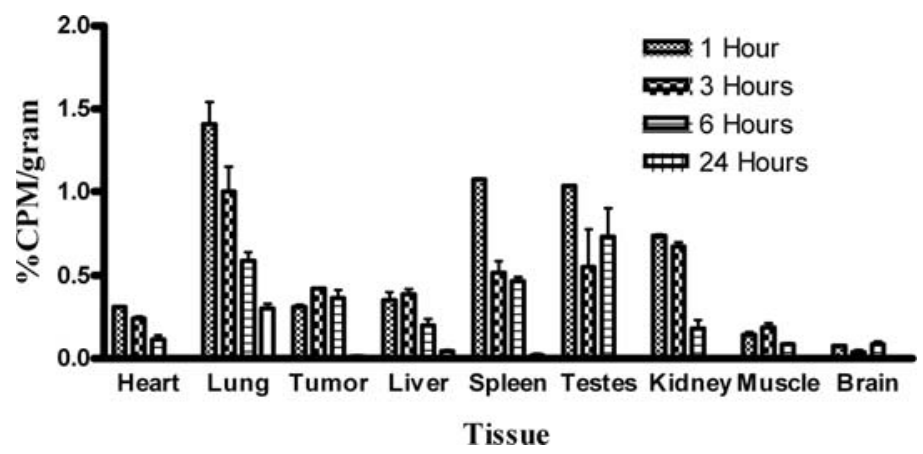

B

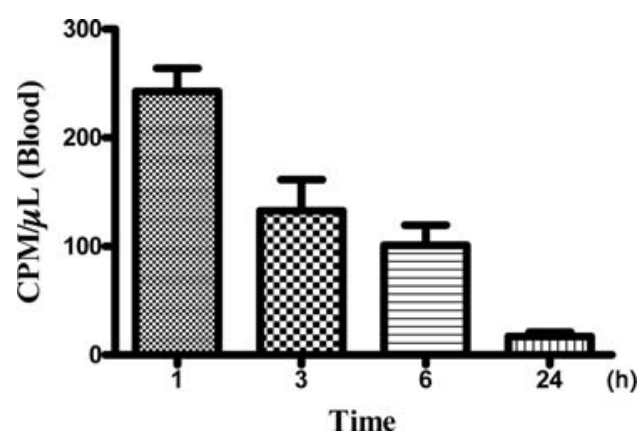

Figure 2. Distribution of the modified peptide in various tissues and blood. Organ uptake of the modified peptide (A) as well as the distribution of the modified peptide in whole blood (B) is shown. $\mathrm{I}^{125}$-labeled peptide $(150 \mu \mathrm{g})$ was subcutaneously injected into each mouse, then tissues were extracted at $1,3,6$ and $24 \mathrm{~h}$. Tissues were then analyzed for the amount of labeled modified peptide via a scintillation counter. The units for the amount of peptide in the various tissues are presented as the \% counts per minute $(\mathrm{CPM}) / \mathrm{g}(\mathrm{A})$, whereas the amount of labeled peptide in the blood was measured as the $\mathrm{CPM} / \mu \mathrm{l}(\mathrm{B})$. 


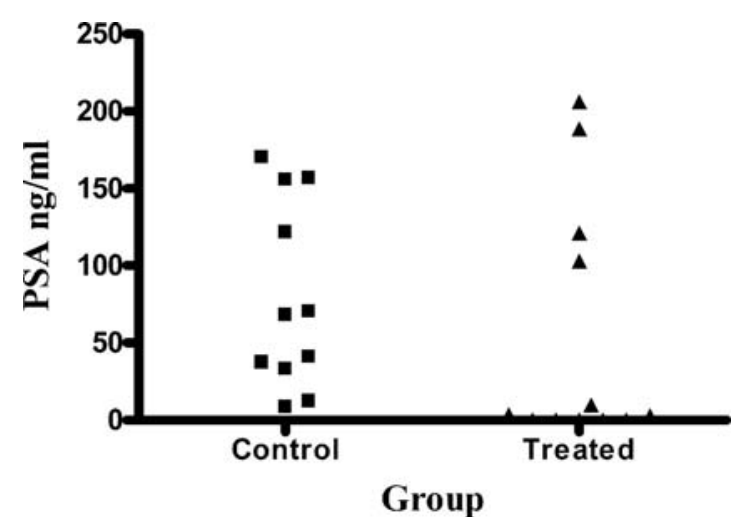

Figure 3. Modified peptide-treated mice had lower prostate-specific antigen (PSA) levels and a decreased incidence of prostate tumors compared to control mice. In the above distribution plot, data were obtained from mice treated with PBS or modified peptide for $\sim 7$ weeks. Mice were injected 2 times/week with $200 \mu \mathrm{l}$ of PBS or $200 \mu \mathrm{g}$ of the modified peptide.

Table I. PSA levels in peptide-treated and control mice after 7 weeks of treatment.

\begin{tabular}{|c|c|c|c|}
\hline \multicolumn{2}{|c|}{ Control group } & \multicolumn{2}{|c|}{ Treated group } \\
\hline $\begin{array}{l}\text { Mouse } \\
\text { no. }\end{array}$ & $\begin{array}{c}\mathrm{PSA} \pm \mathrm{SD} \\
(\mathrm{ng} / \mathrm{ml})\end{array}$ & $\begin{array}{c}\text { Mouse } \\
\text { no. }\end{array}$ & $\begin{array}{c}\mathrm{PSA} \pm \mathrm{SD} \\
(\mathrm{ng} / \mathrm{ml})\end{array}$ \\
\hline 1. & $32.9 \pm 0.7$ & 1. & $3.6 \pm 0.3$ \\
\hline 2. & $8.3 \pm 0.4$ & 2. & $103.0 \pm 1.4$ \\
\hline 3. & $68.0 \pm 8.2$ & 3. & $9.8 \pm 1.2$ \\
\hline 4. & $70.3 \pm 0.1$ & 4. & $3.1 \pm 1.6$ \\
\hline 5. & $12.2 \pm 0.4$ & 5. & $206.1 \pm 7.0$ \\
\hline 6. & $37.2 \pm 0.4$ & 6. & Tumor-free \\
\hline 7. & $40.7 \pm 0.1$ & 7. & Tumor-free \\
\hline 8. & $121.4 \pm 0.2$ & 8. & Tumor-free \\
\hline 9. & $155.6 \pm 5.2$ & 9. & $121.2 \pm 1.2$ \\
\hline 10. & $156.6 \pm 2.6$ & 10. & Tumor-free \\
\hline \multirow[t]{2}{*}{11.} & $170.2 \pm 3.0$ & 11. & $188.7 \pm 14.1$ \\
\hline & & 12. & Tumor-free \\
\hline
\end{tabular}

Approximately 7 weeks after peptide treatment, prostate-specific antigen (PSA) levels were determined in the treated and control mice. The above table shows actual PSA values \pm standard error (SD) $(n=2)$. PSA levels were determined as described in Materials and methods. Average PSA levels were calculated for the control and treated groups. PSA levels in mice without tumors were determined to be $\sim 0$. These mice were included in the calculation of the average PSA level of each group.

\section{Discussion}

The H-3 peptide, derived from the helix 3 domain of the poreforming amoebapore modified at the C-terminal with two $\gamma$-linked glutamates, is designed as an anticancer agent for the treatment of PSMA-positive prostate tumors. Our previous in vitro data showed that modification of the $\mathrm{H}-3$ domain with two $\gamma$-linked glutamate residues at the C-terminal completely abolished cytolytic activity against mammalian cells. The

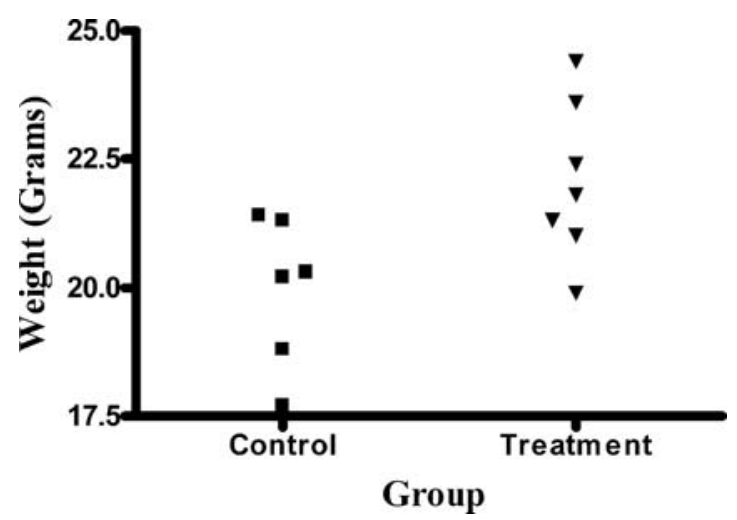

Figure 4. Modified peptide-treated mice had better overall health than the control mice according to body weight. The body mass of the mice was reported after $\sim 7$ weeks of peptide treatment and is presented as a distribution plot. The average body weight of the peptide- treated mice was greater than that of the PBS-treated mice. $\mathrm{P}<0.05$ for the treated vs. untreated group.

Table II. Final body weight of mice after 7 weeks of treatment.

\begin{tabular}{lcccc}
\hline \multicolumn{2}{c}{ Control group } & & \multicolumn{2}{c}{ Treated group } \\
\cline { 5 - 5 } Mouse no. & Weight $(\mathrm{g})$ & & Mouse no. & Weight (g) \\
\hline 1. & 20.3 & & 1. & 21.0 \\
2. & 18.8 & & 2. & 21.3 \\
3. & 21.4 & & 3. & 22.4 \\
4. & 20.2 & & 4. & 21.8 \\
5. & 17.7 & & 5. & 19.9 \\
6. & 21.3 & & 6. & 24.4 \\
& & 7. & 23.6 \\
\hline
\end{tabular}

At the end of the study, body weight was determined for the control and modified peptide-treated mice. The actual values obtained are shown.

modified peptide regained its lytic activity after the two $\gamma$-linked glutamate residues were cleaved by PSMA upon contact with tumor cells (7). In the present study, the in vivo efficacy of the modified peptide against PSMA-positive prostate tumor cells was examined by establishing $\mathrm{LNCaP}$ xenografts in nude mice. Our results show that treatment with the modified peptide reduced the average circulating PSA levels by $\sim 33 \%$ in nude mice with PSMA-positive LNCaP xenografts (Fig. 3 and Table I). Additionally, PSA levels in the peptide-treated group had a very interesting bipolar distribution pattern, with 4 mice having very high PSA levels and 7 having undetectable or very low levels of PSA. Of the 7 treated mice with low PSA levels, 5 were tumor-free. Modified peptide treatment therefore resulted in decreased overall PSA levels and tumor incidence.

When the modified peptide was administered intraperitoneally (i.p.) or intravenously (i.v.), no associated toxicity was observed in single-dose studies at $30 \mathrm{mg} / \mathrm{kg}$. It was also not surprising to note that the accumulation of the peptide in the tumor was not very high, since the peptide was tumoractivated rather than tumor-targeted. Considering the mech- 
anism of pore-forming and fast cell lysis of this peptide, it is possible that many peptide molecules were released into the circulation with the tumor cell debris after being lysed by the peptide. It is also significant that the peptide level in the tumor was maintained at a steady level for $6 \mathrm{~h}$, whereas the peptide levels in most other tissues dropped dramatically. The ability of the peptide to decrease PSMA levels as well as to inhibit tumor growth in 5/12 mice render this peptide a potential candidate for the treatment of prostate cancer.

\section{References}

1. Espey DK, Wu XC, Swan J, et al: Annual report to the nation on the status of cancer, 1975-2004, featuring cancer in American Indians and Alaska Natives. Cancer 110: 2119-2152, 2007.

2. Crawford ED, Rosenblum M, Ziada AM and Lange PH: Hormone refractory prostate cancer. Urology 54: 1-7, 1999.

3. DeFeo-Jones D, Garsky VM, Wong BK, et al: A peptidedoxorubicin 'prodrug' activated by prostate-specific antigen selectively kills prostate tumor cells positive for prostate-specific antigen in vivo. Nat Med 6: 1248-1252, 2000.

4. DeFeo-Jones D, Brady SF, Feng DM, et al: A prostate-specific antigen (PSA)-activated vinblastine prodrug selectively kills PSA-secreting cells in vivo. Mol Cancer Ther 1: 451-459, 2002.

5. Brady SF, Pawluczyk JM, Lumma PK, et al: Design and synthesis of a pro-drug of vinblastine targeted at treatment of prostate cancer with enhanced efficacy and reduced systemic toxicity. J Med Chem 45: 4706-4715, 2002.

6. Wong BK, DeFeo-Jones D, Jones RE, et al: PSA-specific and non-PSA-specific conversion of a PSA-targeted peptide conjugate of doxorubicin to its active metabolites. Drug Metab Dispos 29: 313-318, 2001.
7. Warren P, Li L, Song W, Holle E, Wei Y, Wagner T and Yu X: In vitro targeted killing of prostate tumor cells by a synthetic amoebapore helix 3 peptide modified with two gamma-linked glutamate residues at the $\mathrm{COOH}$ terminus. Cancer Res 61: 6783-6787, 2001.

8. Chandran SS, Nan A, Rosen DM, Ghandehari H and Denmeade SR: A prostate-specific antigen activated N-(2-hydroxypropyl) methacrylamide copolymer prodrug as dual-targeted therapy for prostate cancer. Mol Cancer Ther 6: 2928-2937, 2007.

9. Kratz F, Mansour A, Soltau J, Warnecke A, Fichtner I, Unger C and Drevs J: Development of albumin-binding doxorubicin prodrugs that are cleaved by prostate-specific antigen. Archiv der Pharmazie 338: 462-472, 2005.

10. Schmid B, Chung D, Warnecke A, Fichtner I and Kratz F: Albumin-binding prodrugs of camptothecin and doxorubicin with an Ala-Leu-Ala-Leu-linker that are cleaved by cathepsin B: synthesis and antitumor efficacy. Bioconjug Chem 18: 702-716, 2007.

11. Chung DE and Kratz F: Development of a novel albuminbinding prodrug that is cleaved by urokinase-type-plasminogen activator (uPA). Bioorg Med Chem Lett 16: 5157-5163, 2006.

12. Warnecke A, Fichtner I, Garmann D, Jaehde U and Kratz F: Synthesis and biological activity of water-soluble maleimide derivatives of the anticancer drug carboplatin designed as albumin-binding prodrugs. Bioconjug Chem 15: 1349-1359, 2004.

13. Williams SA, Merchant RF, Garrett-Mayer E, Isaacs JT, Buckley JT and Denmeade SR: A prostate-specific antigenactivated channel-forming toxin as therapy for prostatic disease. J Natl Cancer Inst 99: 376-385, 2007.

14. Kline T, Torgov MY, Mendelsohn BA, Cerveny CG and Senter PD: Novel antitumor prodrugs designed for activation by matrix metalloproteinases-2 and -9. Mol Pharmacol 1: 9-22, 2004. 